\title{
Epidemiological Characteristics of
} Infectious Diseases Among Travelers Between China and Foreign Countries Before and During the Early Stage of the COVID-19 Pandemic

OPEN ACCESS

Edited by:

Ana Afonso,

University of São Paulo, Brazil

Reviewed by:

Yaodong $\mathrm{Gu}$,

Ningbo University, China

Timothy Kudinha,

Charles Sturt University, Australia Vladimira Vasileva Boyadzhieva,

University Hospital St. Ivan

Rilski, Bulgaria

*Correspondence:

Ruiping Wang

w19830901@126.com

Xiaopan Li

xiaopanli0224@126.com

Lile Wu

wbm_bigcat@hotmail.com

tThese authors have contributed equally to this work

Specialty section:

This article was submitted to Infectious Diseases - Surveillance,

Prevention and Treatment,

a section of the journal

Frontiers in Public Health

Received: 12 July 2021 Accepted: 11 October 2021

Published: 03 November 2021

Citation:

Luo Z, Wang W, Ding Y, Xie J, Lu J,

Xue W, Chen Y, Wang R, Li X and

Wu L (2021) Epidemiological

Characteristics of Infectious Diseases Among Travelers Between China and

Foreign Countries Before and During

the Early Stage of the COVID-19

Pandemic.

Front. Public Health 9:739828. doi: 10.3389/fpubh.2021.739828
Zheng Luo ${ }^{1 t}$, Wei Wang ${ }^{2 t}$, Yibo Ding ${ }^{3 t}$, Jiaxin Xie ${ }^{4}$, Jinhua Lu ${ }^{2}$, Wen Xue ${ }^{2}$, Yichen Chen ${ }^{5,6}$, Ruiping Wang ${ }^{7 *}$, Xiaopan $\mathrm{Li}^{5,6 *}$ and Lile $\mathrm{Wu}^{8 *}$

${ }^{1}$ Department of Neurology, Shanghai University of Medicine \& Health Sciences Affiliated Zhoupu Hospital, Shanghai, China, ${ }^{2}$ Department of Infectious Disease Surveillance, Shanghai International Travel Healthcare Center, Shanghai, China, ${ }^{3}$ Department of Epidemiology, Second Military Medical University, Shanghai, China, ${ }^{4}$ Department of High Altitude Operational Medicine, Army Medical University, Chongqing, China, ${ }^{5}$ Office of Scientific Research and Information Management, Center for Disease Control and Prevention, Pudong New Area, Shanghai, China, ${ }^{6}$ Office of Scientific Research and Information Management, Fudan University Pudong Institute of Preventive Medicine, Pudong New Area, Shanghai, China, ${ }^{7}$ Office of Clinical Research Center, Shanghai Skin Disease Hospital, Shanghai, China, ${ }^{8}$ Department of Hepatobiliary Surgery, The Affiliated Hospital of Southwest Medical University, Luzhou, China

Background: International travel during the Coronavirus disease 2019 (COVID-19) pandemic carries a certain magnitude of infection risk both to travelers and their destination, which may be difficult to assess in the early stage. The characteristics of common infectious diseases of tourists may provide some clues to identify the high-risk travelers and protect susceptible population.

Methods: From among 48,444 travelers screened at Shanghai Port, we analyzed 577 travelers with 590 infectious diseases for age, sex, disease type, and World Health Organization $(\mathrm{WHO})$ regions. We used the Joinpoint Regression Program to identify the average percent changes (APC) in the various trends among these individuals.

Results: Hepatitis B, syphilis, and HIV were the most common infectious diseases in travelers entering China, and Hepatitis B, pulmonary tuberculosis, and syphilis in Chinese nationals traveling abroad (overall detection rates, 1.43 and $0.74 \%$, respectively; $P<0.05)$. Africa (2.96\%), the Americas (1.68\%), and the Western Pacific (1.62\%) exhibited the highest detection rates. This trend did not decrease since the COVID-19 pandemic $(P>0.05)$ and rather showed an upward trend with increasing age [APC 95\% $\mathrm{Cl}=5.46(3.41,7.56) \%, P<0.05]$. However, there were no evident trends in monthly infection rates of travelers exiting and entering China from different WHO regions (all $P>0.05)$.

Conclusion: Travelers always carry a transmission risk of common infectious diseases. It may be reasonable to adjust strategies for airport screening and quarantine according to the age and departure area of travelers to prevent and control new infectious diseases.

Keywords: infectious diseases, COVID-19, China, pandemic, Coronavirus 


\section{INTRODUCTION}

With economic globalization and continuous expansion of human activities, the space-time migration patterns among people and between people and animals have gradually changed. Due to the frequent interaction of humans with animals, the boundaries keeping various known or unknown viruses in wildlife from invading the human ecosystem have gradually disappeared $(1,2)$. Human infections from viruses that have undergone a long period of unknown natural selection and evolution in animals may lead to new infectious diseases and bring challenges of unforeseen magnitude to human health (3).

The detection of emerging infectious diseases is challenging, and this limitation makes their control difficult due to the occult transmission $(4,5)$. For example, in the early stages of COVID-19 pandemic, nearly 50\% of COVID-19 cases were not detected in airport screening (4). In addition, the COVID-19 infection data issued by World Health Organization (WHO) is also limited by the release policies for epidemic data and detection strategies in different regions (6). Therefore, we need more indicators to assess the transmission risk of different travelers in order to identify the high-risk travelers, then we can increase the number of airport and post entry screening for those travelers from high-risk regions, and appropriately increase the days of quarantine, so as to reduce the transmission risk (7). Meanwhile, HIV, syphilis, tuberculosis, and other common infectious diseases are often monitored by the entryexit inspection and quarantine departments of each country. This can be done effectively as the pathogens of these diseases are clear and established detection methods are available (7, 8). Although the source and route of transmission of different infectious diseases from infected people are different, the humanto-human spread of viruses usually occurs via droplets, sweat, blood, and other body fluids through contact or airborne transmission $(9,10)$. In particular, understanding the epidemic characteristics of infectious diseases that are common among international travelers will help understand the regional and population differences thereof, understand the demographic and geographical characteristics of infectious patients leaving and entering China, and define the infectious disease prevention and control level of different countries.

In this study, we analyzed the infectious disease disparities in WHO regions or age groups of entry-exit travelers at Shanghai Port before and after Jan 31, 2020 [considering Jan 31 as the time of COVID-19 being identified as a Public Health Emergency of International Concern (PHEIC) by the WHO] (11), and evaluated the temporal trends of the overall detection rate of common infectious diseases and the detection rate of each common infectious disease of Chinese nationals leaving China and travelers entering China by using the joinpoint regression model $(12,13)$, which may provide some clues for identifying the high-risk travelers (10). The results will help us determine whether the number of common infectious diseases is decreasing due to the decrease in the number of international travelers, or whether the infection rate of international travelers is reduced due to the spillover effect of prevention and control measures during the early stage of
COVID-19 pandemic, ascertain the characteristics of infectious diseases in entry-exit travelers coming to China from different regions of the world before and during the early stage of COVID-19 pandemic as the evaluation indicators and provide a reference for discussing the modes of international transmission of emerging infectious diseases. This is particularly true for global cooperation in the prevention and control of COVID-19, which may be the next common infectious disease in human beings (14).

\section{MATERIALS AND METHODS}

\section{Data Source}

Data in this study were acquired from Shanghai International Travel Healthcare Center in Shanghai Port, including the airport and seaport. This center is responsible for the legal work of health management and infectious disease monitoring of entryexit personnel who plan to stay in the place of entry for more than 1 year.

\section{Study Design and Samples}

To evaluate the characteristics of the infectious diseases of entry-exit travelers at Shanghai Port from Jan 1, 2019 to Apr 30, 2020, we conducted a retrospective cohort study by collecting data from the surveillance system in Shanghai International Travel Healthcare Center. During this period, data were collected from 48,444 individuals who were screened for common infectious diseases, including syphilis, HIV, pulmonary tuberculosis, malaria, hepatitis $\mathrm{B}$, hepatitis $\mathrm{C}$, hepatitis $\mathrm{E}$, and infectious comorbidities.

We used the overall detection rate of common infectious diseases and the detection rates of each common infectious disease to compare the disparities between travelers exiting and entering China by age (including each 5-year age group encompassing 15-70 years of age as well as the age groups of $\leq 14$ years and $>70$ years), sex (male and female), disease types, entryexit types (exit/entry), and the WHO region of the nationality of the passenger (South-East Asia, Africa, the Americas, Europe, the Western Pacific, and Eastern Mediterranean and Other territories).

\section{Statistical Analysis}

The detection rates of different groups were calculated and shown as percentages. They were compared according to the Poisson approximation method (15).

Joinpoint regressions have been widely used to analyze potential changes in trends (16). The time series were modeled using a few continuous linear segments, and the weighted sum of squared errors and the choice of the number of joinpoints were minimized on the basis of permutation tests (17). Compared to other regression methods used to investigate trends to find the best-fit line through years of data, the joinpoint analysis tests whether a multi-segmented line is a significantly better fit than a straight or less-segmented line $(18,19)$. Meanwhile, joinpoint analysis provides a much clearer picture of what is happening during a distinct period than a single summary trend statistic (20). Therefore, the study introduced the Joinpoint 
TABLE 1 | Characteristics of infectious diseases among travelers at Shanghai Port, China, Jan 2019-Apr 2020.

\begin{tabular}{|c|c|c|c|c|}
\hline & Cases $(n, \%)$ & Test population $(n, \%)$ & Detection rate (\%) & $\boldsymbol{P}$ \\
\hline \multicolumn{5}{|l|}{ Panel A: All travelers } \\
\hline Status & & & & $<0.001$ \\
\hline Foreigner entry Shanghai & 454 (76.94) & $33,143(68.42)$ & 1.37 & \\
\hline Foreigner exit Shanghai & / & / & I & \\
\hline Hong Kong, Macao and Taiwan Residence entry Shanghai & $28(4.75)$ & $515(1.06)$ & 5.44 & \\
\hline Hong Kong, Macao and Taiwan Residence exit Shanghai & / & / & / & \\
\hline Mainland Chinese entry Shanghai & 0 & $159(0.33)$ & 0 & \\
\hline Mainland Chinese exit Shanghai & $108(18.31)$ & $14,627(30.19)$ & 0.74 & \\
\hline Sex & & & & $<0.001$ \\
\hline Male & 386 (65.42) & $27,095(55.93)$ & 1.42 & \\
\hline Female & $204(34.58)$ & $21,349(44.07)$ & 0.96 & \\
\hline Age & & & & $<0.001$ \\
\hline$<40$ years & $286(48.47)$ & $37,026(76.43)$ & 0.77 & \\
\hline$\geq 40$ years & $304(51.53)$ & $11,418(23.57)$ & 2.66 & \\
\hline Period & & & & 0.06 \\
\hline From Jan 1, 2019 to Jan 31, 2020 & $546(92.54)$ & 45,708 (94.35) & 1.19 & \\
\hline From Feb 1, 2020 to Apr 30, 2020 & $44(7.46)$ & $2,736(5.65)$ & 1.61 & \\
\hline Total & $590(100.00)$ & $48,444(100.00)$ & 1.22 & \\
\hline \multicolumn{5}{|l|}{ Panel B: Travelers entering Shanghai, China } \\
\hline WHO Regions & & & & $<0.001$ \\
\hline South-East Asia & $29(6.02)$ & $2,385(7.05)$ & 1.22 & \\
\hline Africa & $41(8.51)$ & $1,385(4.10)$ & 2.96 & \\
\hline Americas & $116(24.07)$ & 6,649 (19.66) & 1.74 & \\
\hline Europe & $95(19.71)$ & $10,873(32.15)$ & 0.87 & \\
\hline Other territories & $4(0.83)$ & $169(0.50)$ & 2.37 & \\
\hline Western Pacific & $188(39.00)$ & $11,583(34.25)$ & 1.62 & \\
\hline Eastern Mediterranean & $9(1.87)$ & 773 (2.29) & 1.16 & \\
\hline Period & & & & 0.12 \\
\hline From Jan 1, 2019 to Jan 31, 2020 & 443 (91.91) & 31,668 (93.65) & 1.40 & \\
\hline From Feb 1, 2020 to Apr 30, 2020 & 39 (8.09) & $2,149(6.35)$ & 1.81 & \\
\hline Total & $482(100.00)$ & $33,817(100.00)$ & 1.42 & \\
\hline
\end{tabular}

I, Data not shown.

Regression Program 4.0.4 (source: https://surveillance.cancer. gov/joinpoint/) and expressed the changes as average monthly percentage change and average percentage change.

A $\mathrm{Z}$ test was used to assess whether the average monthly percentage change or average percentage change was statistically different from zero (19). All statistical analyses were performed using the Statistical Package for the Social Sciences software version 20.0 (SPSS, Inc., Chicago, IL.). $P$-value $<0.05$ was considered statistically significant.

\section{RESULTS}

\section{Baseline Characteristics}

During the study period, a total of 48,444 travelers were screened for infectious diseases, among whom 577 (1.19\%) travelers tested positive. Among these patients, 33,817 were travelers entering China and 14,627 were Chinese nationals leaving China, which accounted for 482 cases and 108 cases of infectious diseases, respectively (Table 1; Figure 1). The overall detection rate of common infectious disease in Chinese nationals leaving China was lower than that of travelers entering China ( 0.74 vs. $1.43 \%$, $P<0.05)$.

\section{Disparities in Age and WHO Region}

The majority of travelers were 15-29 years old, with the peak age range being 20-24 years (9,640 persons). The majority of individuals with infectious diseases were aged $30-44$ years, the average age was $40.60 \pm 13.11$ years old, and the peak age range was $40-44$ years (81 cases). No child aged under 14 years was detected as having any infectious disease (Supplementary Table 1). The sex-specific detection rate of travelers segregated by months are shown in Supplementary Table 2 . The detection rate of infectious diseases was higher in those aged $\geq 40$ years than in younger individuals $(P<0.05$; Table 1$)$.

The proportion of male travelers was 55.93\%, and the detection rate of infectious diseases was higher in men than in women (65.42 vs. $34.58 \%, P<0.05$; Table 1$)$. 


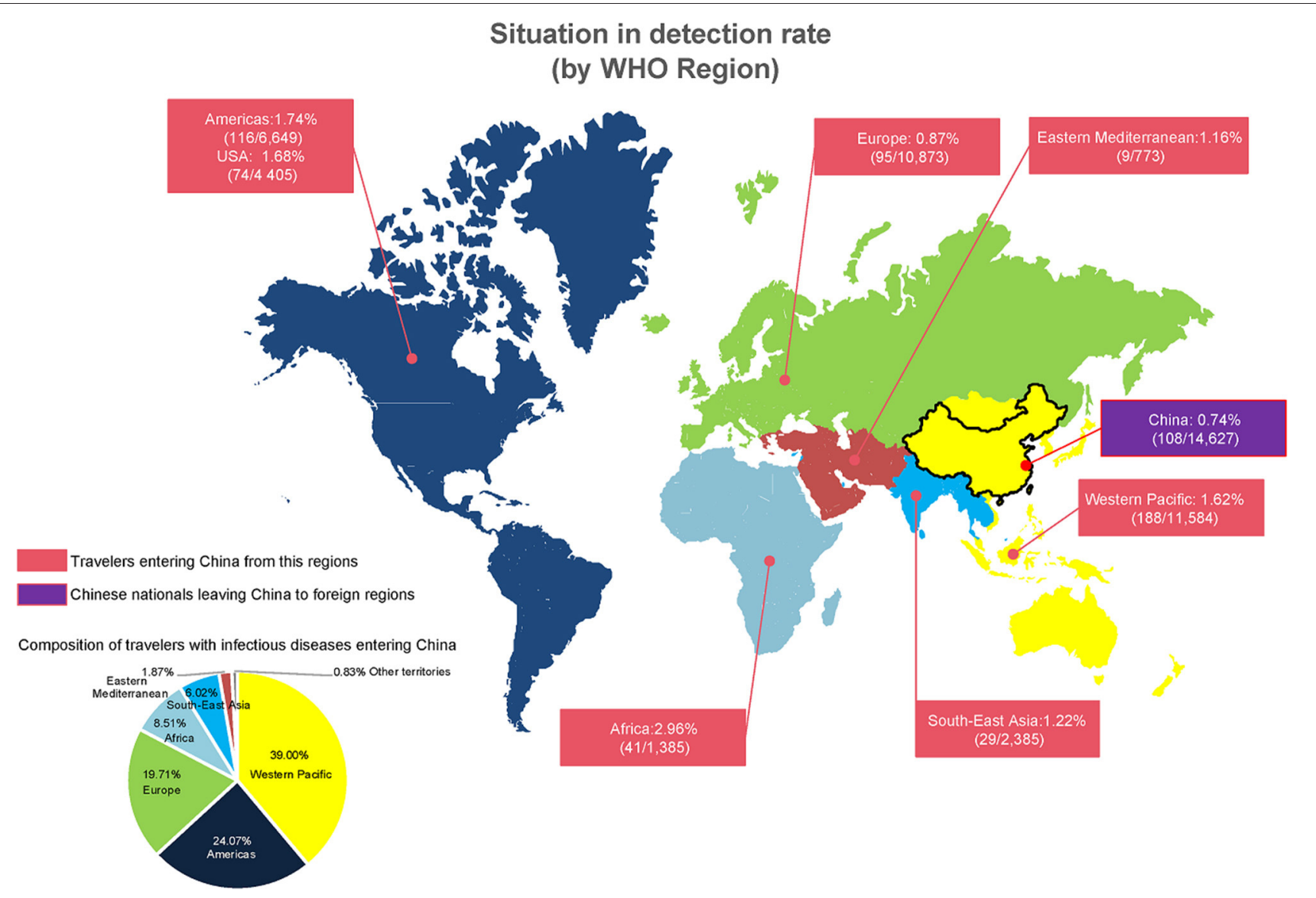

FIGURE 1 | Regional differences in infectious disease cases among travelers at Shanghai Port, China, Jan 2019-Apr 2020.

In the tested population, 33,143 travelers entering China accounted for $68.42 \%$ of cases, and the number of travelers entering and leaving China were higher from Jul to Sept 2019 and decreased after Jan 2020 to about $50 \%$ of what they were in the same period in 2019. The top 3 months with the highest recorded infectious diseases were Sept, Jul, and Apr 2019, and then, the number of infectious diseases detected decreased in 2020 to about $50 \%$ of that in the same period in 2019 (Supplementary Table 2).

In addition, there were no significant differences in the detection rates of travelers entering China before and during COVID-19 pandemic. Similarly, there were no significant differences in the detection rates of travelers entering China during Feb-Apr 2019 and during Feb-Apr 2020 vs. those leaving China during Feb-Apr 2019 and during Feb-Apr 2020 (all $P>0.05$; Table 1, Panel A and Panel B; Supplementary Tables 3, 5). The number of travelers entering China and the monthly detection rates between Jan 31, 2020 and Apr 30, 2020 are shown in Supplementary Table 3. The numbers of travelers from each country or region are shown in Supplementary Table 4, and the detection rates of different infectious diseases are shown in Supplementary Table 5.

The top three original regions of travelers entering into China were the Western Pacific, Europe, and the Americas; however, the highest rate of infection was observed in travelers from Africa, followed by the Western Pacific, and the Americas, with all three regions collectively accounting for $71.58 \%$ of all cases (Figure 1). There were significant differences in the positive detection rate among people from different regions $(P<0.001$; Table 1$)$.

The top three common infectious diseases were hepatitis B, syphilis, and HIV among men, travelers entering China, and travelers $<40$ years old, accounting for 90.67, 91.91, and $85.66 \%$ of all cases, respectively. Similarly, the top three common infectious diseases were (1) hepatitis B, syphilis, and pulmonary tuberculosis among women, accounting for $86.76 \%$ of all cases; (2) hepatitis B, pulmonary tuberculosis, and syphilis among Chinese nationals leaving China, accounting for $84.26 \%$ of all cases; and (3) hepatitis B, syphilis, and hepatitis C among travelers aged $\geq 40$ years. There were statistically significant differences in the spectrum of infectious diseases detected in entry-exit personnel (entering China vs. leaving China, $P=0.001$ ) in terms of sex (male vs. female, $P=0.03$ ) and age ( $<40$ years vs. $\geq 40$ years, $P<0.001$; Figures $2 \mathrm{~A}-\mathrm{C}$ ).

\section{Trend Analysis}

For all travelers, the average detection rate of an infectious disease was $1.22 \%$; the lowest detection rate was $0.12 \%$ in the 
A

$\begin{array}{rcc}\text { Hepatitis B } & 269 & 69.69 \% \\ \text { Syphilis } & 50 & 12.95 \% \\ \text { HIV } & 31 & 8.03 \% \\ \text { Hepatitis C } & 20 & 5.18 \% \\ \text { Pulmonary tuberculosis } & 14 & 3.63 \% \\ \text { Malaria } & 2 & 0.52 \% \\ \text { Hepatitis E } & 0 & 0.00 \% \\ \text { All infectiious disease } & 386 & 100.00 \% \\ \text { Infectious comorbidity } & 10 & 2.67 \%\end{array}$

\section{B}

$\begin{array}{rcc}\text { Hepatitis B } & 358 & 74.27 \% \\ \text { Syphilis } & 56 & 11.62 \% \\ \text { HIV } & 29 & 7.41 \% \\ \text { Hepatitis C } & 24 & 4.98 \% \\ \text { Pulmonary tuberculosis } & 13 & 2.70 \% \\ \text { Malaria } & 1 & 0.21 \% \\ \text { Hepatitis E } & 1 & 0.21 \% \\ \text { All infectiious disease } & 482 & 100.00 \% \\ \text { Infectious comorbidity } & 10 & 2.12 \%\end{array}$

C

$\begin{array}{rcc}\text { Hepatitis B } & 176 & 61.54 \% \\ \text { Syphilis } & 44 & 15.38 \% \\ \text { HIV } & 25 & 8.74 \% \\ \text { Pulmonary tuberculosis } & 21 & 7.34 \% \\ \text { Hepatitis C } & 17 & 5.94 \% \\ \text { Malaria } & 2 & 0.70 \% \\ \text { Hepatitis E } & 1 & 0.35 \% \\ \text { All infectiious disease } & 286 & 100.00 \% \\ \text { Infectious comorbidity } & 7 & 2.52 \%\end{array}$

\section{Males Females}
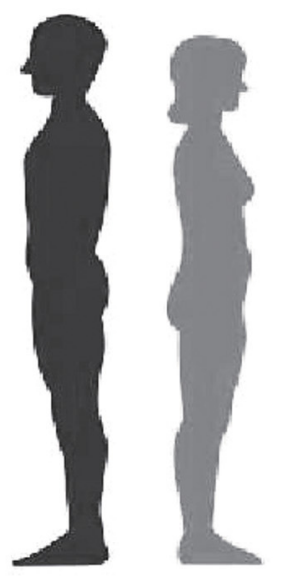

Hepatitis B

$15174.02 \%$

Syphilis

$20 \quad 9.80 \%$

Pulmonary tuberculosis

$14 \quad 6.86 \%$

Hepatitis C

$12 \quad 5.88 \%$

HIV

Hepatitis E

$6 \quad 2.94 \%$

Malaria

All infectiious disease

Infectious comorbidity

$1 \quad 0.49 \%$

o $\quad 0.00 \%$

$204 \quad 100.00 \%$

$2 \quad 0.99 \%$

Entry Exit
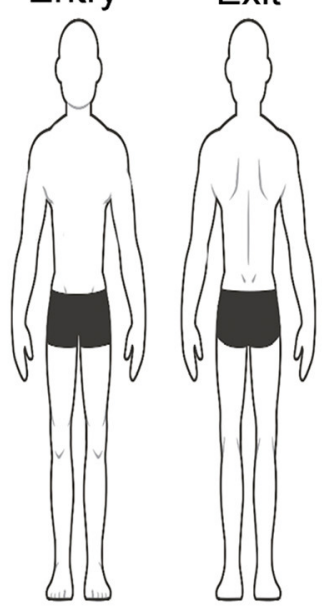

Hepatitis B

$62 \quad 57.41 \%$

Pulmonary tuberculosis

Syphilis

$15 \quad 13.89 \%$

Hepatitis C

HIV

Malaria

Hepatitis E

All infectiious disease

Infectious comorbidity

$14 \quad 12.96 \%$

$8 \quad 7.41 \%$

$8 \quad 7.41 \%$

$1 \quad 0.93 \%$

o $\quad 0.00 \%$

$108 \quad 100.00 \%$

$2 \quad 1.89 \%$

$<40$ yrs $\geq 40$ yrs

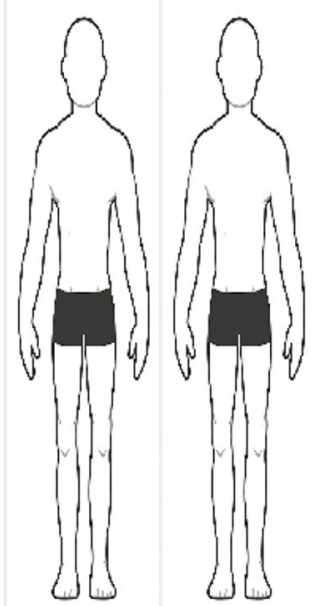

Hepatitis B

Syphilis

Hepatitis C

HIV

Pulmonary tuberculosis

Malaria

Hepatitis E

All infectious disease

Infectious comorbidity
$24480.26 \%$

$26 \quad 8.55 \%$

$15 \quad 4.93 \%$

$12 \quad 3.95 \%$

$7 \quad 2.30 \%$

o $\quad 0.00 \%$

$304 \quad 100.00 \%$

$5 \quad 1.67 \%$ o $\quad 0.00 \%$

FIGURE 2 | Detection spectrum of infectious diseases of travelers at Shanghai Port, China, Jan 2019-Apr 2020 (A) Sex; (B) Entry and exit population; (C) Age group. 


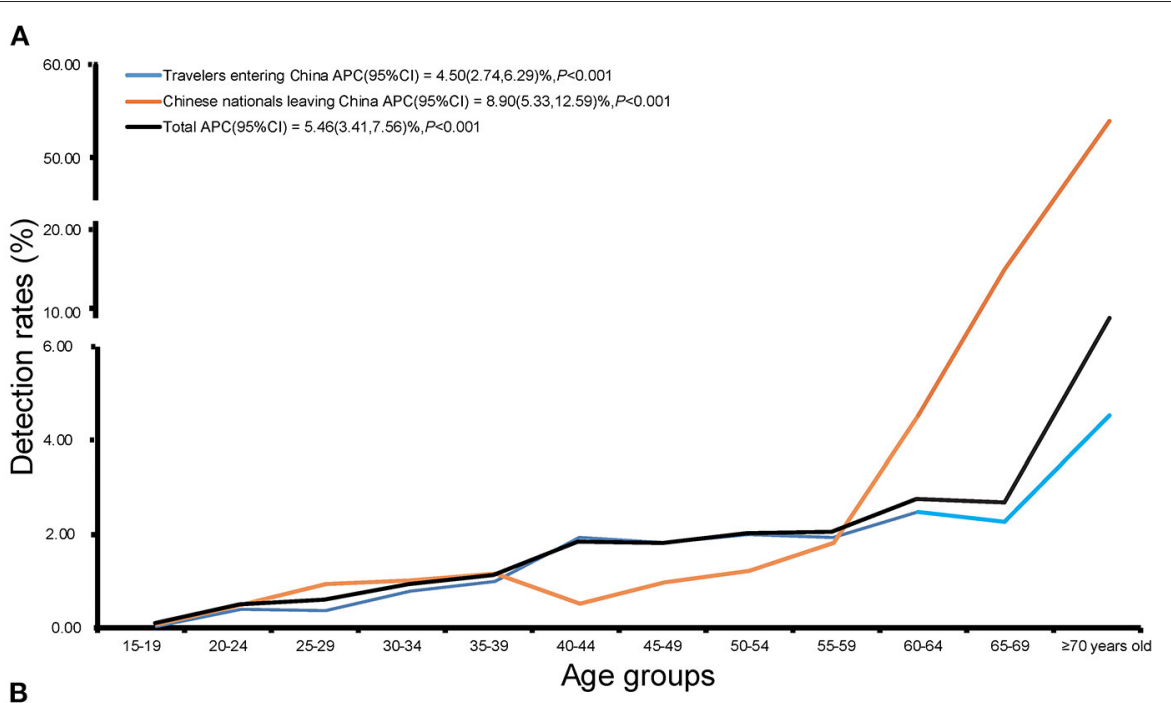

B Age groups

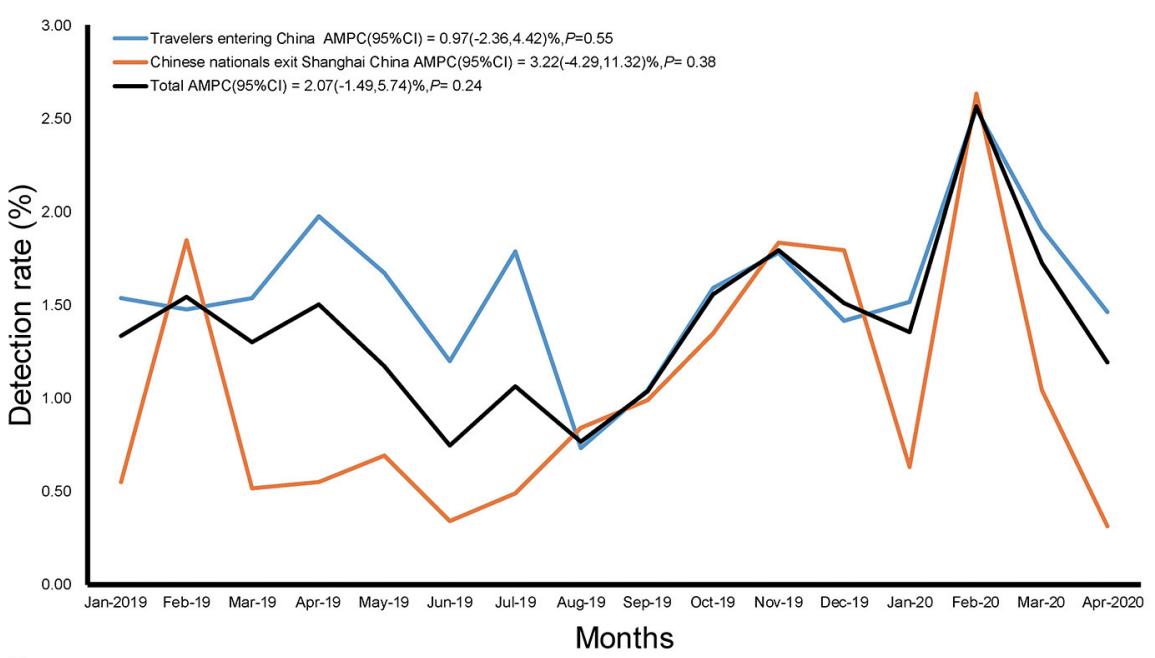

C

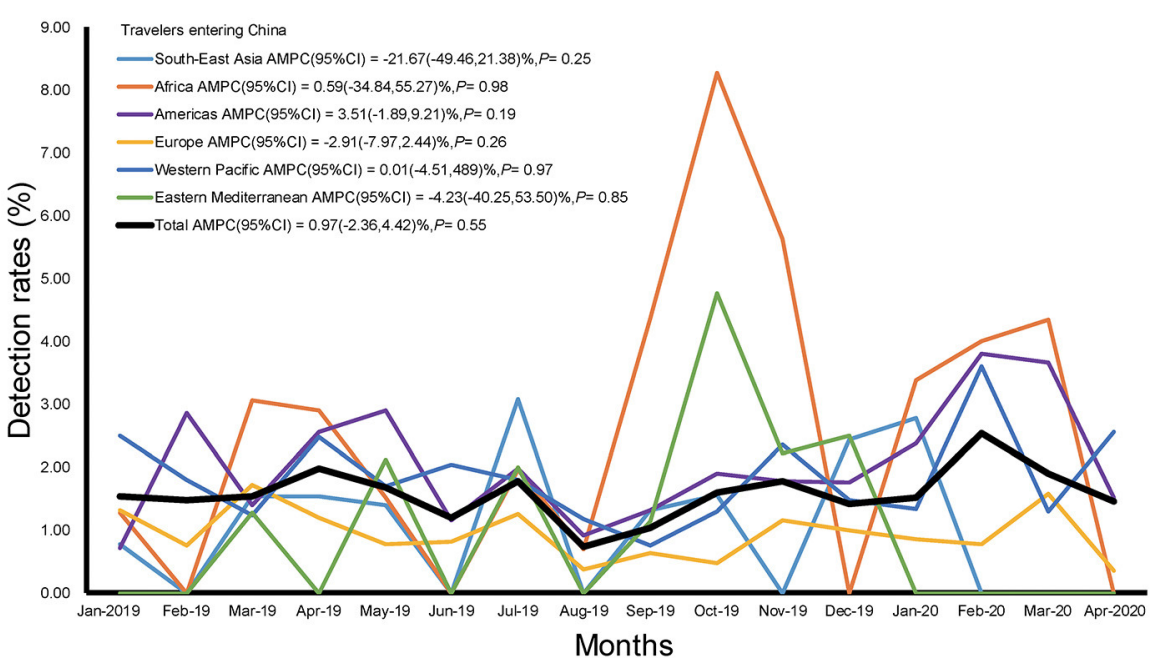

FIGURE 3 | Trend of detection rate of infectious diseases among travelers at Shanghai Port, China, Jan 2019-Apr 2020 (A) Age trends; (B) Time trends; (C) Time trends in each region. 
15-19 years age group; and the highest detection rate was $9.18 \%$ in individuals over 70 years of age. With increasing age, there were a significant overall detection rate [APC 95\% $\mathrm{CI}=5.46(3.41,7.56) \%, P<0.05]$ of common infectious diseases in travelers exiting and entering China throughout the entire period. In addition, the overall detection rate in travelers entering China showed a significant increase of $4.50 \%$ (95\% CI: $2.74,6.29 \%, P<0.001)$, and the overall detection rate in Chinese nationals leaving China showed a significant increase of $8.90 \%$ (95\% CI: 5.33, 12.59\%, $P<0.001$ ). Figure 3A shows the trend of detection rates associated with different age groups for all travelers, travelers entering China, and Chinese nationals leaving China. Supplementary Table 1 shows these detection rates separately for men and women.

The detection rate of infectious diseases with increasing time indicated a fluctuating trend without an obvious increasing or decreasing trend for travelers entering China and for Chinese nationals leaving China on a monthly basis (all $P>0.05$; Figure 3B; Supplementary Table 2). In addition, there was no statistically significant difference in the monthly data of detection rates of infected individuals leaving China (to anywhere), entering China (from anywhere), or entering China (from each WHO region; all $P>0.05$; Figure 3C; Supplementary Table 3 ).

\section{DISCUSSION}

As the number of emerging infectious diseases is increasing, the current global situation of infectious diseases is becoming increasingly severe $(21,22)$. As exemplified by the COVID-19 pandemic, the spread of epidemic diseases not only seriously endangers human health and national economic development but also affects social stability (23). To actively respond to an infectious disease epidemic, the top priority should be aimed at preventing the worldwide spread of the epidemic and at strengthening the prevention and control lines of infectious diseases at ports to prevent the import of overseas cases (24). Among such measures, strategies should be developed to follow closely the global epidemic situation, strengthen epidemic control and risk analysis, improve port health inspection and quarantine protocols, and ensure the surveillance of entry and exit of the infectious diseases $(25,26)$.

To achieve the above-mentioned goals, it is of primary importance that travelers, who are very important to economic development, understand the spread of infectious diseases and the epidemic characteristics of infectious diseases so as to follow the emergency epidemic prevention policies formulated by various countries or regions $(27,28)$. Our results showed that the overall detection rate of common infectious diseases among travelers entering and leaving Shanghai Port of China did not change significantly with time and climate change. Furthermore, the detection rate of different diseases did not significantly differ before and during the early stage of the COVID-19 pandemic. Globally, even though some infectious diseases are seasonal, the overall detection rate of imported and exported common infectious diseases in Shanghai, China has not changed significantly in recent times. Therefore, the Customs officials need to pay attention to the prevention of infectious diseases in both peak season and off-season travel because the enhancement of prevention and control measures to prevent novel emerging infectious diseases has not been able to reduce the infection proportion of common infectious diseases among travelers. Meanwhile, in early stages of the spread of new infectious diseases (e.g., COVID-19), the infection risk may not be completely eliminated by the reduction in the number of travelers alone because of insufficient means to detect the novel infection (3). Furthermore, we would like to particularly emphasize the finding that the proportion of infectious diseases carried by Chinese residents leaving the country was lower than that of infectious diseases carried by people of other regions in the world entering China. This shows that China's public health policy, which implements the principle of modern prevention first, is an effective approach (26). Furthermore, these results show that China's infectious disease prevention and control system operates well and with the aim to prevent and control the infection. This approach thus guarantees the control of the COVID-19 pandemic within the country and is also a basic demonstration of how to prevent the spread of new infectious diseases to other countries (29). Identifying the basic features of common infectious diseases can help people reach a consensus and avoid rumors that result in prejudices $(10,30)$.

We also need to recognize the regional diversities of infectious diseases. Our results show that travelers coming from Western Pacific region have the largest number of detected infectious cases, which can be attributed to this region being responsible for the largest number of travelers coming to China. Furthermore, the travelers entering Shanghai Port of China from Africa have the highest detection rate of infectious diseases, which may be attributed to the lack of local health resources and the relatively higher infection rate in Africa (31). These findings suggest that in the context of international exchanges, the prevention and control of infectious diseases endemic to Africa is an indispensable step in the prevention of global spread of these diseases. These results also suggest that the COVID-19 control in Africa is related to the public health and safety of the world (32-34).

It is also indispensable to understand the international infectious disease spectrum in different populations. The results of this study revealed that in men, the detection rate of HIV was in the third place and tuberculosis was in the fifth place, whereas in women, tuberculosis was in the third place and HIV was in the fifth place. Nevertheless, the absolute number and detection rate of HIV infection were higher in men than in women, which may be associated with the higher exposure level of gay men to HIV (35-37). The results of this study showed that the infection rate of infectious diseases in travelers aged $>15$ years increased with age, and the highest detection rate was noted in travelers aged $>70$ years. The detection rate of common infectious diseases among Chinese residents aged $>70$ years was $57.14 \%$ (4/7). Conversely, these findings may be attributed to the bias caused by the fact that the majority of international tourists were younger than 40 years of age $(76.43 \%)$. The population aged $>60$ years only accounted for $2.56 \%$ of the total population, and the population aged $>70$ years was not sufficient (98 people) for data analysis. This also suggests that the representativeness of the population aged $>70$ years was not large enough. By contrast, the findings in this age group 
may also be related to the opportune accumulation of infectious diseases as this population lived through a time when healthcare policies were weak and vaccines were not popular. These policies may have increased the exposure level of these individuals to pathogens and reduced the body's immunity (38-40). However, the high detection rate of common infectious diseases in the higher age group cannot be underestimated. More than $80 \%$ of the cases in patients aged $>40$ years exhibited hepatitis $B$, which indicated that the prevention and treatment of hepatitis $\mathrm{B}$ among travelers in this age group is very important. This also highlights the protective effect of hepatitis $B$ vaccine on human beings after its introduction, as young travelers were completely free from hepatitis B infection (41). In terms of the entry-exit population, syphilis and HIV among foreign travelers ranked as the second and third most common infections, respectively, while tuberculosis and syphilis among Chinese nationals ranked as the second and third most common infections, respectively. Therefore, it maybe helpful for destination countries to carry out targeted preventive and control measures for travelers exiting and entering China according to the infection spectrum of different common infectious diseases (42-45).

Finally, it is requisite to understand the transmission characteristics of common infectious diseases to overcome the fear of new unknown infectious diseases $(6,46)$. Many new, unknown infectious diseases will eventually transform into common infectious diseases and will require researchers to identify their characteristics and pathogenic mechanism to make medicines available (47). Thus, our results will help countries adjust strategies for airport screening and quarantine according to the age and departure area of travelers to prevent and control new infectious diseases (48).

Our study has some limitations. First, due to different basic reproduction number $(\mathrm{R} 0)$ and source and route of transmission, it is difficult to design control and prevention strategies against emerging infectious diseases (e.g., COVID-19) on the basis of the detection rates of common infectious diseases in international travelers $(26,49)$. However, as our knowledge about COVID19 has increased with time, it can be used as a reference for the prevention and control of other infectious diseases in the future. Second, there were not enough months of monitoring data since the COVID-19 pandemic started because China has taken strict prevention and control measures to greatly reduce the traffic of international travelers after May 2020 (9). In addition, there were no data of the COVID-19 infection in people having common infectious diseases because we had no authority to detect the infection of common infectious diseases of travelers transferred to the hospital immediately due to the diagnosis of COVID-19. More data will be available only when international travel normalizes in the future; however, the future is currently unpredictable. Finally, the infectious disease monitoring of the Customs can only target the travelers who are expected to enter the country for more than 1 year; therefore, a large number of individuals traveling for a shorter period are not included in the monitoring system. This may lead to underestimation of the infection rates because individuals who travel a lot are more likely to harbor an infectious disease $(5,50)$. However, it is gratifying that all travelers are currently being tested for COVID-19 regardless of their stay duration.
Generally, the policy of prevention and control of the international spread of infectious diseases may be based on already known common infectious diseases. Additionally, novel emerging infectious diseases often spread in hiding in the early stages until detection methods for the causative agent are established. We should therefore focus on the regional and population diversities rather than relying on time or climate changes to eradicate infectious diseases. Overall, it is important to strengthen mutual cooperation in the prevention and control of infectious diseases among countries and to restore world order and safe public health.

\section{DATA AVAILABILITY STATEMENT}

The original contributions presented in the study are included in the article/Supplementary Material, further inquiries can be directed to the corresponding author/s.

\section{ETHICS STATEMENT}

Our study did not involve any intervention in human participants. The surveillance protocol was approved by the Ethical Committee of Shanghai International Travel Healthcare Center. Verbal informed consent was obtained from each subject. Individual information was de-identified prior to analysis. Strict confidentiality of individual data was practiced during the entire study.

\section{AUTHOR CONTRIBUTIONS}

XPL, LLW, and RPW designed the research. ZL, WW, YCC, JHL, and WX collected the data. ZL, WW, and YBD performed the research and analyzed the data. XPL, LLW, and ZL wrote the paper. XPL, LLW, RPW, and JXX provided critical revisions. All authors contributed to the article and approved the submitted version.

\section{FUNDING}

This work was supported by a grant from the Key Disciplines Construction Foundation of Health Commission of Shanghai Pudong New District of China (PWZxk2017-25 to ZL), a grant from the project of Shanghai University of Medicine \& Health Sciences Affiliated Zhoupu Hospital (zpxm-2019b05 to $\mathrm{ZL}$ ), a grant from the Reserve Discipline Leader Talents Training Program of the Pudong Center for Disease Control and Prevention (PDCDC-HBXD2020-05 to XPL), a grant from Shanghai Public Health System Construction Three-year Action Plan Outstanding Youth Talent Training Program (GWV-10.2YQ43 to YCC), a grant from the Research Program of Shanghai Sports Bureau (20Q001 to RPW), Key disciplines of public health in Shanghai (GWV-10.1-XK17 to YBD), COVID-19 project of National Natural Science Foundation of China (82041022 to YBD), a grant from the National Natural Science Foundation of China (Grant No. 81803294 to JXX). 


\section{ACKNOWLEDGMENTS}

We would like to thank the colleagues in Shanghai International Travel Healthcare Center who helped us collect data for the study and Medjaden Inc. for scientific editing of this manuscript.

\section{SUPPLEMENTARY MATERIAL}

The Supplementary Material for this article can be found online at: https://www.frontiersin.org/articles/10.3389/fpubh. 2021.739828/full\#supplementary-material

\section{REFERENCES}

1. Taylor-Brown A, Booth R, Gillett A, Mealy E, Ogbourne SM, Polkinghorne A, et al. The impact of human activities on Australian wildlife. PLoS ONE. (2019) 14:e0206958. doi: 10.1371/journal.pone.0206958

2. Arcega-Cabrera F, Norena-Barroso E, Oceguera-Vargas I. Lead from hunting activities and its potential environmental threat to wildlife in a protected wetland in Yucatan, Mexico. Ecotoxicol Environ Saf. (2014) 100:251-7. doi: 10.1016/j.ecoenv.2013.11.002

3. Lythgoe KA, Hall M, Ferretti L, de Cesare M, MacIntyre-Cockett G, Trebes A, et al. SARS-CoV-2 within-host diversity and transmission. Science. (2021) 372:6539. doi: 10.1126/science.abg0821

4. Quilty BJ, Clifford S, Flasche S, Eggo RM. Effectiveness of airport screening at detecting travellers infected with novel coronavirus (2019-nCoV). Euro Surveill. (2020) 25:80. doi: 10.2807/1560-7917.ES.2020.25.5.2000080

5. Joisten C, Kossow A, Book J, Broichhaus L, Daum M, Eisenburger N, et al. How to manage quarantine-adherence, psychosocial consequences, coping strategies and lifestyle of patients with COVID-19 and their confirmed contacts: study protocol of the CoCo-Fakt surveillance study, Cologne, Germany. BMJ Open. (2021) 11:e048001. doi: 10.1136/bmjopen-2020-048001

6. Jalali R, Mohammadi M. Rumors and incorrect reports are more deadly than the new coronavirus (SARS-CoV-2). Antimicrob Resist Infect Control. (2020) 9:68. doi: 10.1186/s13756-020-00738-1

7. Li X, Liu M, Zhou R, Zhang Y, Wu C, Xu L. Centralized medical quarantine for imported COVID-19 in Shanghai, China. J Travel Med. (2020) 27:109. doi: $10.1093 / \mathrm{jtm} /$ taaa109

8. Ulrich MR, Mariner WK. Quarantine and the federal role in epidemics. SMU Law Rev. (2018) 71:391-444.

9. Hu Z, Wu Y, Su M, Xie L, Zhang A, Lin X, et al. Population migration, spread of COVID-19, and epidemic prevention and control: empirical evidence from China. BMC Public Health. (2021) 21:529. doi: 10.1186/s12889-021-10605-2

10. Fu J, Jiang C, Wang J, Li Y, Ying H. To halt the spread of imported coronavirus disease 2019 cases in China: action and challenges. Travel Med Infect Dis. (2021) 39:101913. doi: 10.1016/j.tmaid.2020.101913

11. The Lancet Public H. COVID-19: from a PHEIC to a public mental health crisis? Lancet Public Health. (2020) 5:e414. doi: 10.1016/S2468-2667(20)30165-1

12. Yang S, Wu J, Ding C, Cui Y, Zhou Y, Li Y, et al. Epidemiological features of and changes in incidence of infectious diseases in China in the first decade after the SARS outbreak: an observational trend study. Lancet Infect Dis. (2017) 17:716-25. doi: 10.1016/S1473-3099(17)30227-X

13. Jiang Y, Dou X, Yan C, Wan L, Liu H, Li M, et al. Epidemiological characteristics and trends of notifiable infectious diseases in China from 1986 to 2016. J Glob Health. (2020) 10:020803. doi: 10.7189/jogh.10.020803

14. Mbow M, Lell B, Jochems SP, Cisse B, Mboup S, Dewals BG, et al. COVID-19 in Africa: dampening the storm? Science. (2020) 369:624-6. doi: $10.1126 /$ science.abd3902

15. Salzberg DC, Mann JR, McDermott S. Differences in race and ethnicity in muscular dystrophy mortality rates for males under 40 years of age, 20062015. Neuroepidemiology. (2018) 50:201-6. doi: 10.1159/000488244

16. Martins-Melo FR, Lima Mda S, Ramos AN Jr, Alencar CH, Heukelbach J. Mortality and case fatality due to visceral leishmaniasis in Brazil: a nationwide
Supplementary Table 1 | Detection of age-specific infectious diseases among travelers at Shanghai Port, China, Jan 2019-Apr 2020.

Supplementary Table 2 | Detection of infectious diseases among male and female travelers at Shanghai Port, China, Jan 2019-Apr 2020.

Supplementary Table 3 | Detection of infectious diseases in various regions of travelers at Shanghai Port, China, Jan 2019-Apr 2020.

Supplementary Table 4 | Distribution and detection of infectious diseases among travelers at Shanghai Port, China, Jan 2019-Apr 2020.

Supplementary Table 5 | Detection of infectious diseases in travelers entering or leaving Shanghai Port, China, Jan 2019-Apr 2020.

analysis of epidemiology, trends and spatial patterns. PLoS ONE. (2014) 9:e93770. doi: 10.1371/journal.pone.0093770

17. Kim HJ, Fay MP Yu B, Barrett MJ, Feuer EJ. Comparability of segmented line regression models. Biometrics. (2004) 60:1005-14. doi: 10.1111/j.0006-341X.2004.00256.x

18. Puzo Q, Qin P, Mehlum L. Long-term trends of suicide by choice of method in Norway: a joinpoint regression analysis of data from 1969 to 2012. BMC Public Health. (2016) 16:255. doi: 10.1186/s12889-016-2919-y

19. Chen H, Hao L, Yang C, Yan B, Sun Q, Sun L, et al. Understanding the rapid increase in life expectancy in shanghai, China: a populationbased retrospective analysis. BMC Public Health. (2018) 18:256. doi: 10.1186/s12889-018-5112-7

20. Sung H, Ferlay J, Siegel RL, Laversanne M, Soerjomataram I, Jemal A, et al. Global Cancer Statistics 2020: GLOBOCAN estimates of incidence and mortality worldwide for 36 cancers in 185 countries. CA Cancer J Clin. (2021) 71:209-49. doi: 10.3322/caac. 21660

21. Metcalf CJE, Lessler J. Opportunities and challenges in modeling emerging infectious diseases. Science. (2017) 357:149-52. doi: 10.1126/science.aam8335

22. Abubakar I, Gautret P, Brunette GW, Blumberg L, Johnson D, Poumerol $\mathrm{G}$, et al. Global perspectives for prevention of infectious diseases associated with mass gatherings. Lancet Infect Dis. (2012) 12:66-74. doi: 10.1016/S1473-3099(11)70246-8

23. Feng W, Zong W, Wang F, Ju S. Severe acute respiratory syndrome coronavirus 2 (SARS-CoV-2): a review. Mol Cancer. (2020) 19:100. doi: 10.1186/s12943-020-01218-1

24. Mohamed AA, Mohamed N, Mohamoud S, Zahran FE, Khattab RA, El-Damasy DA, et al. SARS-CoV-2: the path of prevention and control. Infect Disord Drug Targets. (2021) 21:358-62. doi: 10.2174/1871526520666200520112848

25. Zheng S, Fan J, Yu F, Feng B, Lou B, Zou Q, et al. Viral load dynamics and disease severity in patients infected with SARS-CoV-2 in Zhejiang province, China, January-March 2020: retrospective cohort study. BMJ. (2020) 369:m1443. doi: 10.1136/bmj.m1443

26. Zhang S, Diao MY, Duan L, Lin Z, Chen D. The novel coronavirus (SARSCoV-2) infections in China: prevention, control and challenges. Intensive Care Med. (2020) 46:591-3. doi: 10.1007/s00134-020-05977-9

27. Mouchtouri VA, Christoforidou EP, An der Heiden M, Menel Lemos C, Fanos M, Rexroth $U$, et al. Exit and entry screening practices for infectious diseases among travelers at points of entry: looking for evidence on public health impact. Int J Environ Res Public Health. (2019) 16:23. doi: 10.3390/ijerph16234638

28. Yan Y, Shin WI, Pang YX, Meng Y, Lai J, You C, et al. The First 75 Days of Novel Coronavirus (SARS-CoV-2) Outbreak: Recent Advances, Prevention, and Treatment. Int J Environ Res Public Health. (2020) 17:7. doi: 10.3390/ijerph17072323

29. Pan A, Liu L, Wang C, Guo H, Hao X, Wang Q, et al. Association of public health interventions with the epidemiology of the COVID-19 outbreak in Wuhan, China. JAMA. (2020) 61:30. doi: 10.1001/jama.2020.6130

30. Poland GA. SARS-CoV-2: a time for clear and immediate action. Lancet Infect Dis. (2020) 20:531-2. doi: 10.1016/S1473-3099(20)30250-4

31. Daftary A, Mondal S, Zelnick J, Friedland G, Seepamore B, Boodhram R, et al. Dynamic needs and challenges of people with drug-resistant tuberculosis 
and HIV in South Africa: a qualitative study. Lancet Glob Health. (2021) 9:e479-88. doi: 10.1016/S2214-109X(20)30548-9

32. Peeri NC, Shrestha N, Rahman MS, Zaki R, Tan Z, Bibi S, et al. The SARS, MERS and novel coronavirus (COVID-19) epidemics, the newest and biggest global health threats: what lessons have we learned? Int J Epidemiol. (2020) 20:33. doi: 10.1093/ije/dyaa033

33. Oberemok VV, Laikova KV, Yurchenko KA. Fomochkina, II, Kubyshkin AV. SARS-CoV-2 will continue to circulate in the human population: an opinion from the point of view of the virus-host relationship. Inflamm Res. (2020) 69:635-40. doi: 10.1007/s00011-020-01352-y

34. Kapata N, Ihekweazu C, Ntoumi F, Raji T, Chanda-Kapata P, Mwaba $\mathrm{P}$, et al. Is Africa prepared for tackling the COVID-19 (SARS-CoV-2) epidemic. Lessons from past outbreaks, ongoing pan-African public health efforts, and implications for the future. Int J Infect Dis. (2020) 93:233-6. doi: 10.1016/j.ijid.2020.02.049

35. Sia D, Nguemeleu Tchouaket E, Hajizadeh M, Karemere H, Onadja Y, Nandi A. The effect of gender inequality on HIV incidence in Sub-Saharan Africa. Public Health. (2020) 182:56-63. doi: 10.1016/j.puhe.2020.01.014

36. The Lancet H. For the HIV epidemic to end so must gender inequality. Lancet HIV. (2019) 6:e411. doi: 10.1016/S2352-3018(19)30198-5

37. Sun CJ, Anderson KM, Bangsberg D, Toevs K, Morrison D, Wells C, et al. Access to HIV Pre-exposure prophylaxis in practice settings: a qualitative study of sexual and gender minority adults' perspectives. J Gen Intern Med. (2019) 34:535-43. doi: 10.1007/s11606-019-04850-w

38. Usemann J, Alves MP, Ritz N, Latzin P, Muller L. Age-dependent response of the human nasal epithelium to rhinovirus infection. Eur Respir J. (2020) 46:55. doi: 10.1183/13993003.congress-2020.4655

39. Tsuzuki S, Baguelin M, Pebody R, van Leeuwen E. Modelling the optimal target age group for seasonal influenza vaccination in Japan. Vaccine. (2020) 38:752-62. doi: 10.1016/j.vaccine.2019.11.001

40. Namdeo M, Kandel R, Thakur PK, Mohan A, Dey AB, Mitra DK. Old age-associated enrichment of peripheral $\mathrm{T}$ regulatory cells and altered redox status in pulmonary tuberculosis patients. Eur J Immunol. (2020). doi: $10.1002 /$ eji.201948261

41. Posuwan N, Wanlapakorn N, Vongpunsawad S, Sintusek P, Leuridan E, Van Damme $\mathrm{P}$, et al. Comparison of hepatitis B surface antibody levels induced by the pentavalent DTwP-HB-Hib versus the hexavalent DTaP-HB-Hib-IPV vaccine, administered to infants at 2, 4, 6, and 18 months of age, following monovalent hepatitis B vaccination at birth. Vaccine. (2020) 38:1643-51. doi: 10.1016/j.vaccine.2019.12.065

42. Chimungu B, Fu M, Wu J, Huang L, Dai Y, Tang S, et al. Prevalence of sexually transmitted infections among foreigners living in Guangzhou, China: a cross-sectional study (2010-2017). BMC Infect Dis. (2020) 20:345. doi: 10.1186/s12879-020-04995-8
43. Hall BJ, Yang X, Huang L, Yi G, Chan EWW, Tucker JD, et al. Barriers and Facilitators of Rapid HIV and syphilis testing uptake among filipino transnational migrants in China. AIDS Behav. (2020) 24:418-27. doi: 10.1007/s10461-019-02449-0

44. Liao WB, Ju K, Gao YM, Pan J. The association between internal migration and pulmonary tuberculosis in China, 2005-2015: a spatial analysis. Infect Dis Poverty. (2020) 9:5. doi: 10.1186/s40249-020-0621-x

45. Dore GJ, Cowie B. Global Hepatitis B Virus Elimination by 2030: China Is Pivotal and Instructive. Clin Infect Dis. (2020) 20:138. doi: 10.1093/cid/ciaa138

46. Zhai SL, Wei WK, Lv DH, Xu ZH, Chen QL, Sun MF, et al. Where did SARS-CoV-2 come from? Vet Rec. (2020) 186:254. doi: 10.1136/vr.m740

47. Lessler J, Chaisson LH, Kucirka LM, Bi Q, Grantz K, Salje H, et al. Assessing the global threat from Zika virus. Science. (2016) 353:aaf8160. doi: $10.1126 /$ science.aaf 8160

48. Wu D, Wu T, Liu Q, Yang Z. The SARS-CoV-2 outbreak: What we know. Int J Infect Dis. (2020) 94:44-8. doi: 10.1016/j.ijid.2020.03.004

49. Ng OT, Marimuthu K, Koh V, Pang J, Linn KZ, Sun J, et al. SARS-CoV-2 seroprevalence and transmission risk factors among high-risk close contacts: a retrospective cohort study. Lancet Infect Dis. (2021) 21:333-43. doi: 10.1016/S1473-3099(20) 30833-1

50. Fan C, Cai T, Gai Z, Wu Y. The relationship between the migrant population's migration network and the risk of COVID-19 transmission in Chinaempirical analysis and prediction in prefecture-level cities. Int $J$ Environ Res Public Health. (2020) 17:8. doi: 10.3390/ijerph17082630

Conflict of Interest: The authors declare that the research was conducted in the absence of any commercial or financial relationships that could be construed as a potential conflict of interest.

Publisher's Note: All claims expressed in this article are solely those of the authors and do not necessarily represent those of their affiliated organizations, or those of the publisher, the editors and the reviewers. Any product that may be evaluated in this article, or claim that may be made by its manufacturer, is not guaranteed or endorsed by the publisher.

Copyright $\odot 2021$ Luo, Wang, Ding, Xie, Lu, Xue, Chen, Wang, Li and Wu. This is an open-access article distributed under the terms of the Creative Commons Attribution License (CC BY). The use, distribution or reproduction in other forums is permitted, provided the original author(s) and the copyright owner(s) are credited and that the original publication in this journal is cited, in accordance with accepted academic practice. No use, distribution or reproduction is permitted which does not comply with these terms. 